Artículo de investigación

Cuestiones de Filosofía

ISSN: 0123-5095

E-ISSN: $2389-9441$

Vol. $3-\mathrm{N}^{\circ} 21$

Junio - diciembre, año 2017

pp. $87-103$

\title{
Fobia al Estado en Tocqueville y Hayek. Elementos para una arqueología del neo-liberalismo ${ }^{1}$
}

\author{
Tocqueville and Hayek State phobia. Elements for a \\ Neoliberalism archaeology
}

José Ricardo Bernal-Lugo

Universidad La Salle, México

Recepción: 8 de marzo del 2017

Evaluación: 15 de agosto del 2017

Aceptación: 4 de noviembre del 2017

1 José Ricardo Bernal Lugo. Universidad La Salle, México.

Fobia al Estado en Tocqueville y Hayek. Elementos para una arqueología del neo-liberalismo, 


\title{
Resumen
}

En el presente artículo retomamos la noción de "fobia al Estado" utilizada por Foucault para analizar la manera en la que se logró problematizar la acción estatal como una amenaza al desarrollo económico y a la libertad individual en el ámbito de la sociedad civil. A través del estudio de la obra de Tocqueville, mostramos cómo algunos elementos de esta forma de problematización ya se encontraban articulados en los discursos del siglo XIX; sin embargo, en el siglo xx los autores neoliberales radicalizarán la crítica al Estado, el cual opondrán al mercado como la única instancia capaz de procurar las exigencias de la democracia moderna. En ese viraje, los trabajos de Hayek en la obra Caminos de servidumbre adquieren una importancia vital.

\begin{abstract}
This article brings back the notion of 'State phobia' used by Foucault to analyze the way how the State action got to be problematized as a threat to economic development and individual freedom in the civil society field. Through Tocqueville's work analysis, we show how some elements of such problematization process were already articulated in the nineteenth century speeches. However, during the twentieth century, neoliberal authors would radicalize their critique against the State, which would be opposed to the market as the only instance able to fulfill the modern democracy requirements. In this turning point, Hayek's works in The Road to Serfdom get vital importance.
\end{abstract}

Key words: State; market; Freedom; equality; neoliberalism; democracy. 


\section{INTRODUCCIÓN}

En un curso de 1979, titulado "Nacimiento de la biopolítica", Michel Foucault utilizó la expresión "fobia al Estado" para caracterizar una actitud de rechazo al orden estatal, el cual terminaba siendo presentado como una entidad intrínsecamente peligrosa para el desarrollo adecuado de la "sociedad civil" (2009:189). Según el francés, esta posición resultaba bastante problemática, ya que partía de una visión sustancialista que interpretaba al Estado como una realidad estática y no como el efecto de relaciones cambiantes capaces de modificar sus funciones, objetivos y prácticas.

Esto, desde luego, no lo llevaba a reivindicar las bondades del aparato estatal, sino que pretendía escapar a la falsa dicotomía entre estatismo y antiestatismo, cada vez más frecuente en los análisis políticos, para analizar el papel específico que el Estado había cumplido en determinadas circunstancias históricas y en dispositivos de poder-saber concretos. Más que ayudarnos a comprender nuestra realidad política, la "fobia al Estado" impedía dar cuenta de la singularidad de los dispositivos en los que este ocupaba un lugar y un papel determinados, lo cual reducía la complejidad de los fenómenos sociales a un conjunto de generalizaciones "intercambiables", independientemente de la singularidad de las realidades que se intentaban describir (Foucault, 2009:189).

Ahora bien, Foucault localizaba el origen de esta fobia en los autores neoliberales de la primera mitad del siglo xx, concretamente, en el ordoliberalismo alemán desarrollado durante el periodo que va de 1930 a 1945. Para el filósofo francés, la concepción del Estado como una entidad omnipresente (2009:191), atravesada por una dinámica expansiva que terminaría por engullir a "la sociedad civil", era una especie de respuesta a realidades muy específicas como el ascenso del keynesianismo, las políticas del new deal, las decisiones económicas de la Unión Soviética y la influencia de los partidos comunistas. Así, la "fobia al Estado" podría ser concebida como una realidad específica del siglo xx; sin embargo, los trabajos del propio Foucault parecen sugerir que su condición de posibilidad se encuentra un par de siglos atrás.

En realidad, las condiciones que permitieron problematizar al Estado como una instancia cuyo desarrollo intrínseco ponía en riesgo el funcionamiento de la economía y amenazaba la libertad individual en el dominio de la sociedad civil, comenzaron a dibujarse en las décadas finales del siglo XVIII. En las primeras clases del curso de 1979, Foucault acierta al insistir en que el 
desarrollo de la economía política hizo emerger un objeto de estudio, sin el cual resultaría imposible comprender la transformación de nuestra manera de problematizar el Estado: se trataba, desde luego, del mercado entendido como un orden natural autorregulado.

En efecto, el mercado comenzó a ser pensado como una instancia capaz de procesar de forma más eficiente y menos invasiva las relaciones entre los individuos mediante transacciones comerciales presuntamente libres en la segunda mitad del siglo XVIII. No obstante, como señala Karl Polanyi (2009), lo que se ha dado en llamar liberalismo económico solo pudo consolidarse ya entrado el siglo xix, momento en el que fue puesto en el centro de los proyectos políticos de las naciones europeas (p. 192). Con todo, el liberalismo económico no consistía en una simple reivindicación de las posibilidades del comercio frente a los límites del poder burocrático estatal, sino en una serie de convicciones que atañían a la organización social y política de las naciones. Una de ellas, quizá la más importante, era la que afirmaba que los mecanismos jurídicos eran ineficaces, e incluso nocivos, al momento de resolver la llamada "cuestión social" y que, por lo mismo, era preciso que el mercado se hiciera cargo de ella.

Aunque en las páginas que siguen nos sería imposible trazar la historia de este complejo proceso, intentaremos mostrar cómo fue que algunas de las ideas a las que dio lugar este discurso terminaron por definir la forma en que algunos intelectuales liberales representaron los conflictos políticos de su época. En particular, nos interesa mostrar cómo fue que la idea de un orden natural, acechado constantemente por la amenaza del Estado, prefiguró las convicciones políticas de un autor tan importante como Tocqueville, al punto de condicionar su comprensión de las luchas sociales de su tiempo. En efecto, el francés interpretaba la historia de las luchas políticas de su época como la disputa entre los defensores de una libertad individual, que solo podía materializarse en la sociedad civil, y los defensores de una igualdad radical, que no podía sino exigir una participación omnímoda del Estado. En ese sentido, Tocqueville reforzaba una narrativa en la que la búsqueda de la libertad parecía incompatible con la acción del Estado en la esfera social.

De ahí que el análisis de Tocqueville se nos presente como una especie de antecedente de la "fobia al Estado", que será desarrollada por algunos pensadores neoliberales en el siglo Xx, en especial por un autor como Hayek, quien intentará edificar toda su filosofía política en torno a la tradición liberal, en general, y a la concepción de Tocqueville, en particular. Influenciado por los 
acontecimientos de su época, el austriaco terminará por radicalizar sus críticas al Estado hasta reducir la complejidad de los fenómenos sociales a un esquema en el que las dinámicas espontáneas del mercado debían oponerse a una planificación estatal siempre amenazante. No obstante, esta especie de simplificación de los antagonismos que atraviesan el orden social se mostrará como extremadamente eficaz para la construcción de una narrativa política que adquirirá toda su influencia a partir de la década de 1970.

\section{TOCQUEVILLE: LIBERTAD VS. IGUALDAD}

Al final de El antiguo régimen y la revolución, Tocqueville (2004) escribió un capítulo titulado "Cómo los franceses quisieron Reformas antes de querer libertades". En dicho texto, el filósofo hacía explícita una de las razones que, desde su perspectiva, explicaban el relativo fracaso de la Revolución francesa: "Es digno de ser destacado el hecho de que, entre todas las ideas y todos los sentimientos que prepararon el camino a la Revolución, la idea y el amor a la libertad pública propiamente dicha fueran los últimos en presentarse y los primeros en desaparecer" (p. 191).

En efecto, según Tocqueville, si la Revolución francesa no había logrado hacer florecer una sociedad tan admirable como aquella que comenzaba a surgir en los Estados Unidos, se debía, sobre todo, a que el amor por la libertad no se había arraigado en el corazón de los revolucionarios franceses. Desde su perspectiva, a diferencia de lo que había ocurrido en Inglaterra durante los siglos XVII y XVIII, los franceses se sintieron menos atraídos por las dulces mieles de la libertad que por la necesidad de reinventar la sociedad.

De hecho, el autor de La democracia en América creía encontrar el origen de esta desafortunada situación en las ideas de los economistas franceses anteriores a la Revolución, quienes, embelesados con proyectos de reformas sociales y administrativas, ignoraron por completo la importancia de las libertades políticas. Así, a pesar de haber sido partidarios del laissez faire, autores como Quesnay, Mercier de la Rivière o el propio Turgot, seguían siendo presos de una visión de la sociedad en la que el Estado mantenía un poder casi absoluto sobre sus súbditos.

Según Tocqueville, cuando Turgot o Quesnay señalaban que el Estado no debía limitarse a gobernar la nación, sino comenzar a "moldearla", estaban ayudando a cimentar las bases de una nueva forma de tiranía. Una tiranía que, al perseguir la ilusión de la igualdad radical, terminaría por legitimar 
el uso del poder estatal para restringir por completo la libertad de los seres humanos. Aunque desde nuestras coordenadas políticas nos parezca un verdadero oxímoron, Tocqueville no dudaba en bautizar esta nueva tiranía como una forma de "despotismo democrático":

Esta forma particular de tiranía que se llama despotismo democrático, de la que la Edad Media no tenía idea, le es familiar a los economistas. No más jerarquías en la sociedad ni separación de clases, ni rangos fijos; sino un pueblo compuesto por individuos casi semejantes y enteramente iguales, esa masa confusa reconocida como el único soberano legítimo, pero cuidadosamente privada de todas las facultades que pudieran permitirle dirigir o incluso vigilar por sí misma su gobierno (2004:196).

Es cierto que para los liberales del siglo XIX los fisiócratas eran una especie de reformadores del antiguo régimen que valoraban al Estado por encima de las libertades de los individuos. Sin embargo, Tocqueville daba un paso adelante al establecer una línea de continuidad entre "los economistas franceses" y las corrientes más nefastas de la revolución de 1789 cuya influencia llegaría hasta el deplorable año de 1848. De esta forma, según el autor de Memorias del pauperismo, el ala jacobina de la Revolución habría heredado de los economistas su desprecio por las libertades públicas y su afán por reformar la sociedad a partir de las instituciones del Estado.

Desde el enfoque de Tocqueville, antes de emancipar a los seres humanos de los yugos impuestos por el antiguo régimen, antes incluso de reivindicar la libertad en el ámbito de la sociedad civil, los jacobinos buscaron asegurar la igualdad material de los seres humanos en nombre de la "soberanía popular". Entonces, al priorizar la igualdad material sobre las libertades políticas, los revolucionarios más radicales habían sacado de cauce un acontecimiento político que en su origen no podía más que ser elogiado.

Esta conclusión se encontraba ya en la introducción del primer tomo de $E l$ antiguo régimen y la revolución, en el que Tocqueville prefiguraba la temática de los volúmenes que debían dar continuidad a su proyecto. Aunque finalmente los libros posteriores no vieron la luz, desde un inicio el francés había esbozado las causas que, en su opinión, llevaron a su estrepitoso fracaso a la revolución de 1789:

[En los volúmenes siguientes] comenzaré recorriendo esa primera época de 1789 , en la que el amor a la igualdad y el amor a la libertad se reparten su corazón; esa época en la que no sólo quieren fundar instituciones 
democráticas, sino instituciones libres; cuando no sólo anhelan destruir privilegios, sino reconocer y consagrar derechos (...). Siguiendo rápidamente el curso de esa revolución, trataré de exponer los acontecimientos, errores y desengaños que indujeron a esos mismos franceses a abandonar su primer objetivo y a desear sólo ser siervos iguales del amo del mundo olvidándose de la libertad (2004:27).

Además de establecer una división tajante entre un bando inclinado hacia la "igualdad" radical y otro favorable a la "libertad", Tocqueville (2004) distinguía entre instituciones democráticas, por un lado, e instituciones libres, por el otro. Unas líneas más adelante, identificaba la "soberanía popular" con la expresión de un "sufragio de electores que no pueden ilustrarse" y se refería a la eliminación del sufragio censitario impuesta por el gobierno jacobino como "el asentamiento de asambleas mudas y sojuzgadas" (p. 27). Con lo cual, resultaba más o menos sencillo establecer una oposición entre unos revolucionarios radicales, que en el concepto de soberanía popular encontrarían un pretexto para defender sus deseos de igualdad extrema, y unos revolucionarios prudentes, a los que se debían las conquistas más "preciosas y nobles" de 1789, a saber, "la libertad de pensar, de hablar y de escribir".

Al presentar las cosas de esta manera, Tocqueville podía reforzar su convicción de que existía una continuidad evidente entre tres proyectos políticos de la Francia moderna: 1) El afán de reformar la sociedad desde el Estado, propia de los economistas franceses del siglo XVIII. 2) La insistencia de los jacobinos en una forma de gobierno, cuya legitimidad estaba sostenida exclusivamente sobre la "soberanía popular" y que, debido a la ausencia de otros controles institucionales, amenazaba las libertades de los hombres. c) Las preocupantes teorías socialistas que ponían en riesgo tanto la propiedad privada como la libertad individual.

De ahí que, para Tocqueville, el socialismo naciente en la década de 1830 no fuera sino una versión refinada de aquellas ideas fraguadas por los economistas franceses del siglo XVIII y defendidas por los sectores radicales de la revolución de 1789: aunque, sin duda, más peligrosa:

Se suele creer que las teorías destructivas con el nombre de socialismo son de origen reciente. Es un error, tales teorías son contemporáneas de los primeros economistas. Mientras éstos empleaban el gobierno omnipotente con el que soñaban cambiar la forma de la sociedad, los otros se apoderaban con la imaginación del mismo poder para destruir sus cimientos (2004:197). 
Pero, ¿a qué se refería Tocqueville al señalar que esta doctrina ponía en riesgo los cimientos de la sociedad? En su famoso discurso pronunciado ante la Asamblea Nacional en agosto de 1848, con motivo de su rechazo al derecho al trabajo, el francés arremetía contra las doctrinas socialistas al afirmar que se fundaban en un ataque directo a los "principios evidentes de la propiedad individual ${ }^{2}$ ". En realidad, Tocqueville consideraba que, en sus afanes igualitarios, las "falaces doctrinas socialistas" buscaban imponer leyes que negaban la libertad de los hombres al tratar de controlar la propiedad privada desde el Estado.

En particular, Tocqueville le reprochaba a la Comisión de Luxemburgo, encabezada brevemente por Louis Blanc después de la revolución de febrero, el haber confundido el papel de las obligaciones jurídicas con aquel que le correspondía a la caridad ${ }^{4}$. En efecto, los republicanos sociales habían defendido distintos mecanismos para ofrecer trabajo a los desempleados, así como para enfrentar la terrible situación en que se encontraba la llamada question social; sin embargo, Tocqueville (2015) estaba convencido de que todo intento de resolver por mecanismos estatales la situación de miseria del pueblo francés era una manera de invadir las facultades que le correspondían a la caridad: “(...) la Commission se borne à imposer à la société le devoir de venir en aide, soit par le travail, soit par le secours proprement dit et dans les mesures de ses ressources, à toutes les misères; (...) l'État (...) a voulu accroître, consacrer, régulariser la charité publique" (p. 36). ${ }^{5}$

Ahora bien, según el francés, al transgredir la línea que dividía la caridad de las obligaciones sociales no solo peligraban instituciones como la propiedad privada y la libertad de los individuos, también se veía amenazado

\footnotetext{
2 Un tipo de propiedad que, según Tocqueville, había existido desde los inicios de la humanidad hasta que el primer socialista dijo que "la propiedad es el origen de todos los males de este mundo". Sin duda, aquí Tocqueville se refiere a Rousseau, a quien presenta como uno de los padres del socialismo.

3 Para el francés, las posturas de los socialistas manifestaban "un prófond mepris pour l'individu pris en lui-même, à l'état d'homme", y sus propuestas no eran otra cosa que una tentativa "variada, continua, incesante", por "mutilar" la libertad humana (Tocqueville, 2015:41).

4 En sus Souvenirs, Tocqueville (2003) recordaba las jornadas de junio de 1848 como una confrontación lamentable pero "necesaria", producto de las "falsas teorías" socialistas que enseñaban a los pobres una errada concepción del derecho, según la cual, "la desigualdad era moralmente condenable" (pp. 862ss.).

5 " $[\ldots]$ la Comisión se limita a imponer a la sociedad el deber de ayudar, sea mediante el trabajo, sea mediante la asistencia propiamente hablando y en la medida de sus recursos, todas las miserias; [...] El Estado [...] ha intentado crecer, consagrar, regularizar la caridad pública". La traducción es del autor del presente documento.
} 
el funcionamiento del orden natural del mercado. De este modo, en su célebre discurso, Tocqueville (2015) se centraba en los dos escenarios económicos que la aprobación del derecho al trabajo podría traer consigo. En el primero de ellos, el Estado se vería obligado a ser un actor industrial para poder garantizar el trabajo de todos los ciudadanos; sin embargo, al hacerlo, terminaría por eliminar toda competencia y se convertiría en "el propietario único de todas las cosas":

[...] 1'État entreprendra de donner à tous les travailleurs qui se présenteront à lui l'emploi qui leur manque, et alors il est entraîné peu à peu à se faire industriel ; et comme il est l'entrepreneur d'industrie qu'on rencontre partout, le seul qui ne puisse refuser le travail, et celui qui d'ordinaire impose la moindre tâche, il est invinciblement conduit à se faire le 'principal, et bientôt, en quelque sorte, l'unique entrepreneur de l'industrie. Une fois arrivé là, l'impôt n'est plus le moyen de faire fonctionner la machine du gouvernement, mais le grand moyen d'alimenter l'industrie. Accumulant ainsi dans ses mains tous les capitaux des particuliers, $1^{\prime}$ Etat devient enfin le propriétaire unique de toutes choses (p. 36).

La otra opción, igualmente execrable para Tocqueville, no resultaba muy diferente: en lugar de volverse un actor industrial, el Estado tendría que reglamentar el trabajo por encima de los imperativos de la competencia, lo que sustituiría la capacidad del mercado para organizar el trabajo en función de las exigencias de la oferta y la demanda:

$\mathrm{Si}$, au contraire, l'Etat veut échapper à la nécessité fatale dont je viens de parler, s'il veut, non plus par lui-même et par ses propres ressources, donne du travail à tous les ouvriers qui se présentent mais veiller à ce qu'ils en trouvent toujours chez il les particuliers, il est entraîné fatalement à tenter cette réglementation de l'industrie qu'adoptait, si je ne me trompe, dans son système, 1'honorable préopinant. Il est obligé de faire en sorte qu'il n'y ait pas de chômage ; cela le mène forcément à distribuer les travailleurs de maniéré à ce $q u$ 'ils ne se fassent pas concurrence $(c / n)$, à régler les salaires, tantôt à modérer la production, tantôt à l'accélérer, en un mot, à le faire le grand et unique organisateur du travail $(2015: 37-38)^{6}$.

\footnotetext{
6 " $\mathrm{Si}$, por el contrario, el Estado desea escapar a la necesidad fatal de la que acabo de hablar, si desea, dar trabajo a todos los obreros que se presentan ya no por sí mismo y sus propios recursos sino procurando que siempre lo encuentren con los particulares, será llevado fatalmente a mantener esta reglamentación de la industria que, si no me equivoco, adoptaba en su sistema, el honorable orador anterior. Está obligado a hacer las cosas de tal forma que no haya desempleo; se ve llevado a forzosamente a distribuir los trabajadores de manera que no haya competencia, a reglamentar los salarios, tanto a moderar la producción como a acelerarla, en una palabra, a ser el gran y único organizador del trabajo". La traducción es del autor del presente documento.
}

Fobia al Estado en Tocqueville y Hayek. Elementos para una arqueología del neo-liberalismo, 
Así, la incorporación del derecho al trabajo defendida por los republicanos sociales terminaría impidiendo que la demanda laboral se regulara a sí misma por el único mecanismo efectivo: la competencia. Ahora bien, como Tocqueville consideraba que la inserción de las demandas sociales al ámbito del derecho era un verdadero peligro, afirmaba que la verdadera disyuntiva que el derecho al trabajo le presentaba a los miembros de la Asamblea no era otra que la de definir si la revolución de febrero había sido una revolución socialista: "On le dit, on le répète; combien de fois, derrière les barricades de juin, n'ai-je point entendu sortir ce cri: vive la république démocratique et sociale? (...) Nous avons besoin de savoir si la révolution de Février est une révolution socialiste" $(2015: 39){ }^{7}$

Desde luego, Tocqueville defendía que no era así pues la revolución de febrero no podía ser contraria a la liberta y, sobre todo, tan mundana como para tener en su centro un problema tan insignificante como el de las necesidades materiales. En efecto, además de su intento de someter el mercado a la "Ley", el socialismo se caracterizaba, según Tocqueville, por un llamado constante a "las pasiones materiales del hombre" que, desde su perspectiva, no estaban a la altura de una verdadera revolución:

Est-ce, [le droit au travail] comme on l'a prétendu tant de fois, la continuation, le complément légitime, le perfectionnement, de la révolution française? Estce, comme on l'a dit tant de fois, le complément, le développement naturel de la démocratie? Non, messieurs c'est ni l'un ni l'autre; rappelez-vous messieurs, la révolution française; remontez à cette origine terrible et glorieuse de notre histoire moderne (...). Est-ce don en parlant (...) aux sentiments matériels, aux besoins matériels de l'homme, que la révolution française a fait les grandes choses qui l'ont illustré dans le monde? Croyez-vous donc que c'est en parlant de salaire, de bien-être, de consommation illimitée, de satisfaction sans bornes des besoins physiques (...). Non, messieurs, non; c'est en parlant de choses plus hautes et plus belles (...) c'est en parlant de vertu, de générosité, de désintéressément, de gloire, qu'elle a fait ces grandes choses $(2015: 39)^{8}$.

\footnotetext{
7 "Se ha dicho, se ha repetido, ¿cuántas veces, detrás de las barricadas de junio, he escuchado ese grito: viva la república democrática y social? [...] Debemos saber si la revolución de Febrero es una revolución socialista". La traducción es del autor del presente documento.

8 "¿Es el derecho al trabajo, como se ha pretendido tantas veces, la continuación, el complemento legítimo, el perfeccionamiento de la revolución francesa?, ¿es, como se ha dicho tantas veces, el complemento, el desarrollo natural de la democracia? No, señores, no es ni lo uno ni lo otro; recuerden señores la revolución francesa; remóntense a ese origen terrible y glorioso de nuestra historia moderna [...] ¿Es hablando [...] de sentimientos materiales, de necesidades materiales del hombre, que la revolución francesa ha realizado las grandes cosas que la han hecho ilustre ante el mundo? Creen ustedes que es hablando de salario, de bienestar, de consumo ilimitado, de satisfacción sin límites de las necesidades físicas [...]. No, señores, no; es hablando de cosas más
} 
Esta perspectiva, con evidentes tintes aristocráticos, le permitía vincular la "gloriosa" tarea de la revolución con la negativa a regular jurídicamente el dominio del mercado o, como Tocqueville lo llamaba, el orden natural de la sociedad. Asimismo, mediante un hábil movimiento teórico, Quesnay, Rousseau, Louis Blanc, Robespierre, Saint Just o Cabet, quedaban confinados en una misma casilla que determinaba el polo al que debía oponerse un régimen verdaderamente moderno, que respetara la libertad y que mantuviera la "gloria" de la política francesa. En el fondo, aseguraba Tocqueville, de Rousseau a Louis Blanc, el anhelo de una sociedad igualitaria dirigida enteramente por el Estado amenazaba el orden natural del mercado, ponía en riesgo las libertades políticas y la propiedad del individuo, al tiempo que rebajaban las aspiraciones del pueblo francés a las pasiones materiales.

En los hechos, las propuestas tanto de los republicanos sociales como de los socialistas eran sumamente diversas e infinitamente más complejas ${ }^{9}$, no obstante, al definir las coordenadas de la disputa política en estos términos, las luchas posrevolucionarias de Francia terminaban por ser subsumidas en una narrativa relativamente controlable, una narrativa binaria guiada por una tensión entre los defensores de una ilusión igualitaria y estatista, por un lado, y quienes reivindicaban la libertad y la autonomía de los individuos, por el otro

\section{Hayek: mercado vs planificación}

Aunque Tocqueville tenía adversarios políticos muy concretos, algunos elementos cruciales de esta narrativa pueden rastrearse en autores del siglo $\mathrm{xx}$, en particular en aquellos que intentaban oponerse al "intervencionismo estatal" que, en la primera mitad del siglo xx, volverá a presentarse como la principal amenaza a la libertad. Así, tanto quienes buscaban una renovación del liberalismo supuestamente derrotado, debido al ascenso de los partidos socialistas, al éxito del keynesianismo y el new deal, como los críticos de los llamados Estados totalitarios, retomarán un tipo de narrativa en la que la intervención del Estado se presenta, al mismo tiempo, como un obstáculo para el funcionamiento adecuado del Estado y como una amenaza a la libertad.

\footnotetext{
altas y más bellas [...], es hablando de virtud, de generosidad, de desinterés, de gloria, que ella ha hecho grandes cosas". La traducción es del autor del presente documento.

9 Un panorama general de estas perspectivas puede encontrarse en: Harvey, D. (2010). París, capital de la modernidad. Madrid: Akal.
} 
En 1943, Friedrich Hayek publicó su famoso libro Caminos de servidumbre, una obra que lo llevaría a ser nombrado presidente de la Sociedad Mont Pèlerín y a granjearse el respeto de buena parte de los autores liberales de la época. Hayek planteaba su propia obra como un intento de recuperar la tradición liberal que, desde su perspectiva, se encontraba agonizando en la Europa de mediados del siglo xx. Para el economista austriaco, los culpables de esa agonía eran fácilmente identificables: las políticas de planificación estatal y el marxismo en cualquiera de sus versiones, incluida la socialdemocracia.

De hecho, diez años antes de la publicación de Caminos de servidumbre, Hayek había intentado mostrar que el emergente nacional socialismo alemán no era otra cosa sino la expresión de las ideas de corte marxista, que desde hace años habían inundado el panorama alemán: "La persecución de marxistas y de demócratas en general tiende a ocultar el hecho fundamental de que el nacional-socialismo es un verdadero movimiento socialista, cuyas ideas directrices son el fruto último de las tendencias antiliberales que han encontrado un terreno firme en Alemania ${ }^{10}$ (Audier, 2012:216).

De hecho, el desarrollo posterior del nazismo será interpretado por Hayek como una confirmación de los peligros inherentes a las ideas socialistas y un llamado urgente a recuperar la tradición liberal. Como hiciera Tocqueville un siglo atrás, la narrativa del austriaco partirá de una visión dicotómica, en la cual el "olvido de la libertad" jugará un papel fundamental. Sin embargo, en su caso, será la pérdida de las "ideas esenciales" de la civilización europea, encarnadas en la libertad económica, la que terminará por explicar el ascenso de los totalitarismos:

El punto decisivo, que las gentes apenas han reconocido todavía, no es ya la magnitud de los cambios ocurridos durante la última generación, sino el hecho de significar una alteración completa en el rumbo de nuestras ideas y nuestro orden social. Al menos durante los veinticinco años anteriores a la transformación del espectro del totalitarismo en una amenaza real, hemos estado alejándonos progresivamente de las ideas esenciales sobre las que se fundó la civilización europea. Que este movimiento, en el que entramos con tan grandes esperanzas y ambiciones, nos haya abocado al horror totalitario, ha sido un choque tan profundo para nuestra generación, que todavía rehúsa relacionar los dos hechos. Sin embargo, esta evolución no hace más que confirmar los avisos de los padres de la filosofía liberal que todavía profesamos.

${ }_{10}$ La traducción es del autor del presente documento. 
Hemos abandonado progresivamente aquella libertad en materia económica sin la cual jamás existió en el pasado libertad personal ni política. Aunque algunos de los mayores pensadores políticos del siglo XIX, como De Tocqueville y Lord Acton, nos advirtieron que socialismo significa esclavitud, hemos marchado constantemente en la dirección del socialismo. Y ahora, cuando vemos surgir ante nuestros ojos una nueva forma de esclavitud, hemos olvidado tan completamente la advertencia, que rara vez se nos ocurre relacionar las dos cosas (Hayek, 2008:56).

Allí donde Tocqueville había habilitado la oposición entre libertad e igualdad, Hayek hará aparecer una distinción tajante entre la "libertad espontánea", ejemplificada por el funcionamiento del mercado, y la racionalización planificadora, vinculada a la intervención del Estado. De manera análoga a los economistas del siglo xIX, el austriaco señalará los peligros inherentes a la intervención del Estado en la economía, solo que planteará esta amenaza como la de una "racionalización" organizada desde el "Estado" en contra de la acción libre y espontánea de los individuos. De ahí que su defensa del mercado tuviera menos que ver con la creencia neoclásica de un equilibrio perfecto, que con lo que él denominaba "beneficios de la libertad" (Lessnof, 2011:174).

En realidad, para Hayek, antes que otra cosa, el mercado era un sistema de información constituido espontáneamente por una multiplicidad de actores sociales. Intervenir en él no solo implicaba una forma de distorsión a la naturaleza de la economía, sino un intento de definir de antemano las decisiones libres que la gente tomaba al incorporarse en su dinámica. En el fondo, eso era lo que más atemorizaba a Hayek pues, desde su perspectiva, una vez que el Estado decidía la oferta de tal o cual producto, terminaría decidiendo sobre sus gustos $\mathrm{y}$, finalmente, sobre su libertad:

En una economía dirigida, donde la autoridad vigila los fines pretendidos, es seguro que ésta usaría sus poderes para fomentar algunos fines y para evitar la realización de otros. No nuestra propia opinión acerca de lo que nos debe agradar o desagradar, sino la de alguna otra persona, determinaría lo que hiciésemos. Y como la autoridad tendría poder para frustrar todos los esfuerzos encaminados a eludir su guía, casi con tanta eficacia intervendría en lo que consumimos como si directamente nos ordenase la forma de gastar nuestros ingresos. La voluntad oficial conformaría y «guiaría» nuestras vidas diarias (Hayek, 2008:107). 
Además de definir nuestras elecciones en el consumo, la planificación racional también determinaría la producción en su conjunto. Con lo cual, la asignación de los trabajos estaría controlada por el Estado, lo cual limitaría la libertad que el mercado ofrece para emplearnos donde deseemos y llevaría hasta el extremo la pérdida de nuestra individualidad:

No seremos ya libres para conducirnos racional y eficientemente tan sólo donde y cuando nos parezca oportuno, tendremos que ajustarnos todos a las normas que la autoridad planificadora deberá fijar para simplificar su tarea. Para poder desempeñar esta inmensa tarea tendrá que reducir la diversidad de las capacidades e inclinaciones humanas a unas cuantas categorías de unidades fácilmente intercambiables y deliberadamente despreciará las diferencias personales menores (Hayek, 2008:109).

Si se observa con atención, el argumento de fondo no difería con la idea de Tocqueville, según la cual, el derecho al trabajo terminaría por llevar al Estado a controlar la producción en su totalidad; pero, como Hayek había definido el mercado como sistema de información sostenido gracias a la actividad de todos sus participantes, también señalaba que era imposible que un solo sujeto pudiera planificar conscientemente ese cúmulo de información sin imponerse arbitrariamente sobre todos los individuos. Entonces, resultaba sencillo mostrar que cualquier intento de planificación en el mecanismo espontáneo del mercado terminaba por convertirse en un sistema dictatorial:

La mayoría de los planificadores que han considerado en serio los aspectos prácticos de su tarea apenas dudan que una economía dirigida tiene que marchar por líneas más o menos dictatoriales. Una consecuencia de las ideas que fundamentan la planificación central, demasiado evidente para no contar con el asentimiento general, es que el complejo sistema de actividades entrecruzadas, si va a ser dirigido en verdad conscientemente, tiene que serlo por un solo estado mayor de técnicos, y que la responsabilidad y el poder últimos tienen que estar en manos de un general en jefe, cuyas acciones no puedan estorbarse por procedimientos democráticos (Hayek, 2008:101).

Por lo mismo, Hayek concluía que dirigir la economía requería que el Estado interviniera a tal punto en las actividades de los individuos que no pudiera dejar espacio a la deliberación democrática. Así, con todas sus limitaciones, los sistemas regulados por la "libre espontaneidad" de los individuos eran totalmente preferibles a la "racionalización económica", una "racionalización" que no podía sino negar la democracia y la libertad. 
Ahora bien, a diferencia de lo que ocurría con Tocqueville, cuyos adversarios eran los incipientes movimientos asociacionistas o un republicanismo social confuso, Hayek hacia frente a realidades mucho más potentes y, desde su perspectiva, mucho más amenazantes: las políticas del new deal implementadas por el Estado norteamericano después de la crisis del 29, las teorías keynesianas que los Estados nación comenzaban a aplicar en aras de garantizar el pleno empleo, la fuerza de poderosos sindicatos organizados desde principios de siglo y, sobre todo, la amenaza siempre latente del comunismo soviético. Todos estos elementos eran interpretados por él como la expresión de la decadencia de nuestro tiempo, una decadencia tanto más peligrosa cuanto ponía en riesgo la libertad individual y apuntaba hacia la planificación estatal de todos los ámbitos del orden social.

Frente a estas propuestas que amenazaban la diversidad de los gustos y apelaban a la univocidad de una planificación centralizada, el mercado se presentaba como el ejemplo más claro de la libertad, como el espacio en el que las elecciones personales tenían pleno valor. Ahora bien, cabía preguntarse si el mercado no debía servir como modelo para la organización de una sociedad democrática en la que los individuos pudieran ejercer su plena libertad de elección. En efecto, el mercado representaba un verdadero ejemplo democrático, pues era un sistema organizado espontáneamente gracias a la actividad libre de una pluralidad de actores sociales que, sin la necesidad de ningún tipo de coacción externa, se regulaban gracias a la información vertida por los individuos en las interacciones comerciales.

esto, Entonces, debía concluirse que las aspiraciones democráticas podían materializarse mejor cuanto más se asemejara la sociedad al funcionamiento del mercado. Ciertamente, el Estado no debía desaparecer por completo, pero tenía que limitarse a establecer reglas que le otorgaran certidumbre a las interacciones individuales y evitar intervenir en ellas mediante cualquier intento de planificación. No obstante, ocurría que, tanto para Hayek como para buena parte de los autores ordo y neoliberales posteriores, la situación de las sociedades desde la década de 1930 estaba marcada por una interferencia constante del Estado que impedía el desarrollo espontáneo de las fuerzas del mercado y, por ende, del individuo. Ante lo anterior, por paradójico que pudiera parecer, una de las principales tareas del Estado era propiciar las condiciones necesarias para el desarrollo del mercado (Escalante, 2015:237ss.).

Por otro lado, el elogio de Hayek hacia las virtudes democráticas del mercado parecía sugerir que el nuevo liberalismo no debía limitarse a devolverle 
aquellas funciones económicas que el Estado se había arrogado ilegítimamente, sino que aspiraba a reorganizar la sociedad en su conjunto como un mercado. Esta posibilidad no dejará de rondar la cabeza de buena parte de los intelectuales del siglo xx, quienes, como Milton Friedman o Richard Posner, desarrollarán múltiples propuestas para mercantilizar la educación, los servicios públicos, el sistema de salud, etcétera. De manera que, lo que Foucault denomina como "fobia al Estado" no solo hará patente un intento de limitar la intervención ilegítima del Estado en el "orden natural" del mercado, sino que paulatinamente dará lugar a la reivindicación de un modelo de sociedad que aspire a funcionar como si se tratara de un mercado.

\section{CONClusiones}

En la obra de Hayek pueden reconocerse sin dificultad algunas ideas que ya podían leerse en un autor como Tocqueville durante el siglo XIX, muy particularmente, la asunción de que la intervención del Estado en la oferta de productos implicaba una interferencia en el funcionamiento del mercado y una amenaza a la libertad de los individuos. En ese sentido, los desarrollos del neoliberalismo en el siglo xx encuentran una de sus condiciones de posibilidad en el hecho de que el liberalismo decimonónico lograra problematizar la idea misma de mercado y sus efectos en la organización social y política. En la oposición planteada por Hayek entre la planificación estatal y la libertad del mercado, no es difícil reconocer algunos de los resabios de la narrativa tocquevilleana, que contraponía las aspiraciones igualitarias supuestamente estatistas del socialismo a la libertad individual, el respeto a la propiedad u al orden natural del mercado.

Sin embargo, los autores del siglo xIX nunca cruzaron el umbral que Hayek traspasó en su trabajo filosófico, como un presagio de los tiempos venideros. En efecto, al presentar al mercado como un sistema, cuyo funcionamiento operaba en sí mismo de forma democrática, el austriaco le abrió las puertas a una narrativa que aún hoy goza de buena salud en algunos sectores sociales. Una narrativa, según la cual la mejor forma de garantizar las aspiraciones democráticas de las sociedades modernas consiste en limitar cualquier forma de intervención planificada del Estado al tiempo que se avanza hacia la adopción de las formas mercantiles y empresariales en las distintas instancias de organización social. 


\section{REFERENCIAS}

Audier, S. (2012). Néo-liberalisme(s), une archéologie intelectuelle. París: Bernard Grasset.

Bernal, R. (2016). Fraternidad y democracia en la modernidad política. En Ambriz, G, Bernal, R. (Coord.) El Derecho contra el capital. México: Contraste.

Escalante, F. (2015). Historia mínima del neoliberalismo. México: El Colegio de México.

Foucault, M. (2009). Nacimiento de la biopolítica. Madrid: Akal.

Harvey, D. (2010). París, capital de la modernidad. Madrid: Akal.

Hayek, F. (2008). Caminos de servidumbre. Madrid: Unión Editorial.

Lessnof, M. (2011). La filosofía política del siglo XX. Madrid: Akal.

Polanyi, K. (2009). La gran transformación. México: Juan Pablo Editor.

Tocqueville, A. (2003). Lettres choises. Souvenirs. París: Gallimard.

----- (2004). El antiguo régimen y la revolución. Madrid: Alianza.

------ (2015). Contre le droit au travail. París: Les belles lettres. 